\title{
Primary Scheme of VMMSCC Text for Re- conceptualizing Pre-service Elementary School Teachers' Conceptions
}

\author{
Neni Hermita \\ Universitas Pendidikan Indonesia \\ Bandung, Indonesia \\ neni.hermita@lecturer.unri.ac.id
}

\section{Ernawulan Syaodih}

Universitas Pendidikan Indonesia

Bandung, Indonesia

ernawulansy@gmail.com

\author{
Andi Suhandi \\ Universitas Pendidikan Indonesia \\ Bandung Indonesia \\ andi_sh@upi.edu \\ Achmad Samsudin \\ Universitas Pendidikan Indonesia \\ Bandung, Indonesia \\ achmadsamsudin@upi.edu
}

\begin{abstract}
Visual Multi-Media Supported Conceptual Change Text (VMMSCCText) has been developed to represent the neutral object concept turn into more real and meaningful learning. The primary design of VMMSCCText is a multimedia computer that allows users to explore the complete neutral object concept in terms of the present conceptual and practical. Pre-service elementary school teachers should be provided with the learning that might enhance the conceptions thought by re-conceptualizing concepts in the basic concept of science, specifically the concepts about static electricity. To collect and to analyze the data sincerely and systematically, researchers used a developing method of ADDIE which has comprehensive steps: analyzing, design, development, implementation, and evaluation. The ADDIE developing steps used to define systematically from the phase of analysis sequencer up until the evaluation sequencer. Based on data analysis, it can be determined that VMMSCCText could successfully increase understanding for re-conceptualizing about neutral object conceptions on pre-service elementary school teachers'.
\end{abstract}

Keywords-VMMSCCText; remediation; misconception; neutral object; elementary school teachers'

\section{INTRODUCTION}

Nearly all concepts qualified in the pre-service elementary school teacher are related to the everyday life as these learners do not appear the physics periods as a tabula rasa [1], [2]. Earlier they happening to go to university and after the university times, while they are going to university, learners learn from their environment with distinct experiences. These distinct experiences multiply different mental structures about the concepts. But, on some cases, everyday life can deceive young minds. Ref. [2] defined the prior knowledge of the learners about the concepts as naïve knowledge and giving to them this knowledge is often wrong. This knowledge which is not constructed on a scientific ground may cause misconceptions. Ref. [3], [4] described the duration misconception as the knowledge which engagements with the scientific knowledge. In physics, there are many common misconceptions and several educations on these misconceptions indicated that it is hard to adjust young minds [4]. Really when a group of learners collects in a class and only one lecturer attempts to find their individual misconceptions, it can be interesting to restructure the conceptual schemas of the learners. On the further influence, as stated [5], the probability that a lecturer can also have misconceptions should not be gone.

One of the alternatives ways for removing misconceptions is using computer-supported instructional materials in a classroom [6]. Computer-supported instructional materials provide students to learn with their speeds, facilitate learning, and gives opportunities to repeat the course contents out of school. Courses handled with computer-supported instructional materials should be supported with pictures, videos, virtual experiment environments, animations, etc., [7 - 9]. Utilizing computers in classrooms have also effects on students' effective learning.

Therefore, there is an essential for a substance which could reorganize conceptual constructions of the learners. This substantial must be simply available and simply available and must advantage from previous knowledge of the learners. Though the use of this material, learners must comprehend both old and new experiences on a scientific basis. Ref. [10] developed the conceptual change texts (CCT) by adopting the stages of the conceptual change theory proposed by [5], [11]. CCT purposes at helping learners to change their misconceptions with scientific concepts. Rendering to [10], phases of CCText through questions to the relevant individuals 
with the purpose of discovery their existing misconceptions (dissatisfaction), challenge to existing misconceptions by using analogies (intelligibility), give the formal definitions of the concepts (plausibility) and provide new conditions for applying the new concept (fruitfulness). Several additional researchers have considered on the CCText since the study of Roth. Several studies $[11,13,14,15,16,17]$ about the CCText and physics concepts. Simply Ref. [11] studied on the CCText by comparing them to the traditional texts (TT) in physics and current the texts in their studies. This directs that there is not enough suggestion display that CCText are more effective in reorganizing the misconceptions. The persistence of this study is to develop a tested conceptual change text which can help lecturers guide their learners to reorganize their misconceptions only by reading a text. Based on the research-background, we have been developing a Visual Multi-Media Supported Conceptual Change Text (VMMSCCText) since 2016. The subject of the conceptual change text is a neutral object and the target misconception is "neutral objects are objects that have no electrical charger" [18], [19].

\section{METHODS}

The ADDIE model of research methods has been utilized to develop Visual Multi-Media Supported Conceptual Change Text (VMMSCCText), which includes the steps of Analyzing, Design, Development, Implementation, and Evaluation. The development of VMMSCCText through ADDIE model has been applied to the pre-service elementary school teacher, as consequently the students were able to be identified hold the existing concept. The research was accompanied by the academic year 2016/2017 at the PGSD FKIP Riau University.

\section{RESULTS AND DISCUSSIONS}

The development of Visual Multi-Media Supported Conceptual Change Text (VMMSCCText) on the neutral object concepts is highlighting on the conceptual approach to re-conceptualize pre-service elementary school teachers more expansively understanding the concepts. Furthermore, VMMSCCText development will be discussed as follows.

\section{A. Analyzing}

The analyzing step was a process of needs assessment such the stage to identify the research problems (needs) and to perform tasks' analyze. The output of the analyzed process was more emphasis on conceptual teaching through the use of a multimedia computer. Based on further analysis, researchers have been obtained the development of VMMSCCText. Analyses were also conducted on "SAP" or learning plan and syllabus of the Calculus-based basic concept of science at that moment researchers totally conducted a fundamental revision of the "SAP" and the existing syllabus. The "SAP" and syllabus have been developed based on a conceptual approach through a VMMSCCText. With the existence of a fundamental revision of the curriculum and syllabus, the analyzing process produced the developing VMMSCCText shown more emphasis on the concept of a neutral object.

\section{B. Design}

This step was known as making a blue-print, similar with the building before it is built there should be a design on paper first. Design in question is the design of VMMSCCText used in learning. VMMSCCText design concept focused on static electricity concept especially in the main concept of the neutral object via simulations, figure, and videos. This VMMSCCText design includes science concepts such as; atoms, static electricity and matter. An example of a multimedia design developed in VMMSCCText in the form of storyboards is presented in Fig 1.

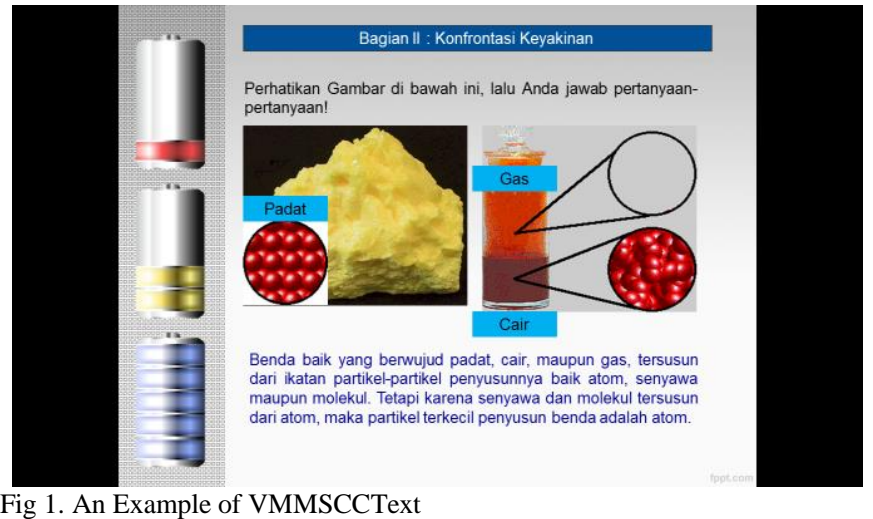

\section{Development}

The development step is the process of realizing the blueprint or design had become a reality. This means that at this step everything needed or that would support the learning process should have been well prepared. As an example of the design, the development phase has been prepared based on multimedia shape as the following example:

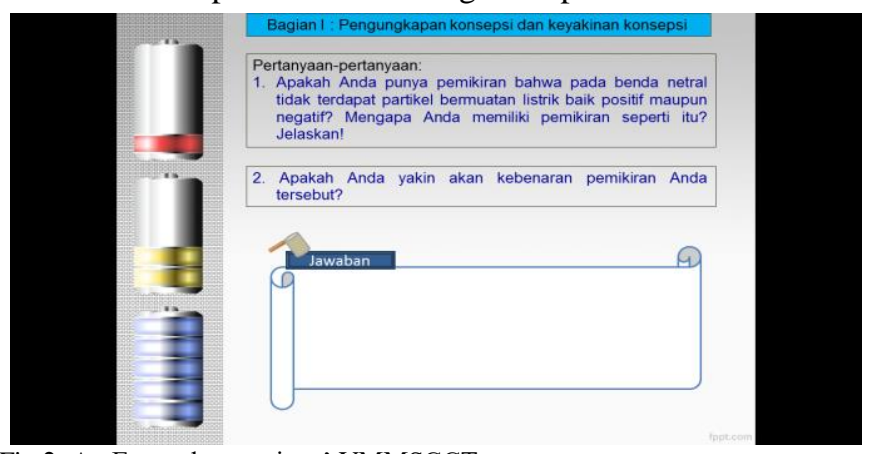

Fig 2. An Example questions' VMMSCCText

The development was undertaken involving the development design and VMMSCCText content. VMMSCCText design that was developed using the program Flash MX and Java Applet were independently developed by the researchers and there were also used Physics Education Technology (PhET) Simulation and others. 


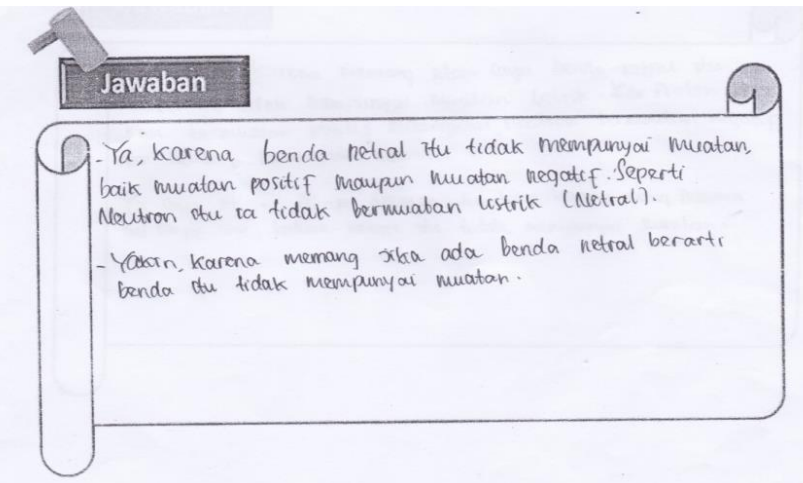

Fig 3. An Example students' answer VMMSCCText

\section{Implementation}

Implementation is the real step to implement a learning system that is being created. That is, at this step all that has been developed is installed or set in such a way appropriate to the role or function to be implemented. Once the product is ready, self-educated learning then re-evaluated and revised so as to produce a final product that is ready to be disseminated. But at the initial design VMMSCCText is only done on a small group trial and evaluation. Here is an example of the implementation of the VMMSCCText in Basic Science Concept.

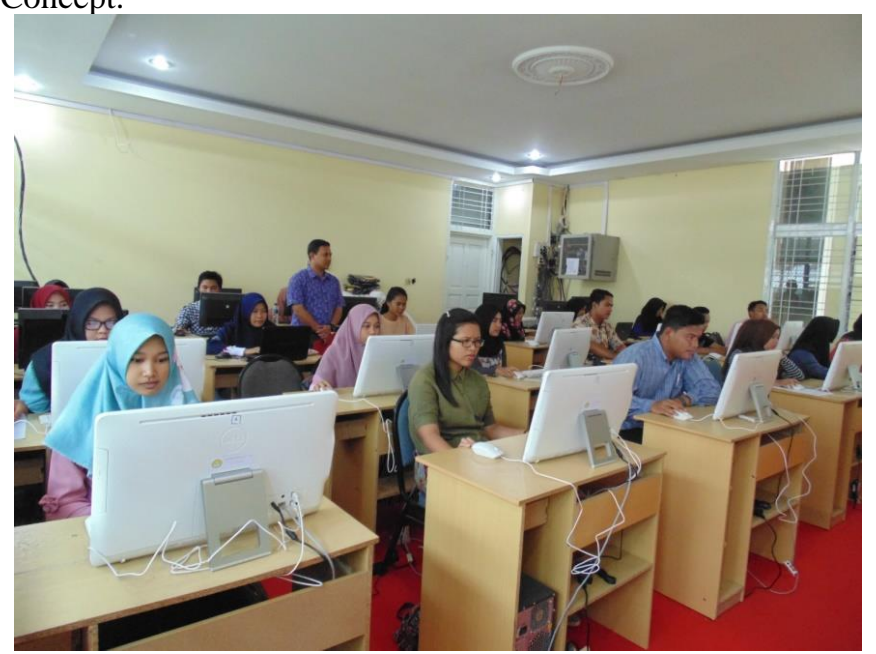

Fig 4. The Implementation VMMSCCText

\section{E. Evaluation}

Evaluation is the process of learning to understand whether the system is being constructed effectively, conferring to preliminary anticipations or not. Evaluation step was intelligent to be carried out at each of the four steps over the supposed formative evaluation because this step typical was evaluated in implementing the process. For the sample in the implementation step desired practiced reviews to give input to the drawn from the tap that was being made. This could be seen in the use of aspects of VMMSCCText could be used at home and in the classroom. In adding, VMMSCCText was also used as a focus on the learning activities in the prior stage. The effectiveness of learning using VMMSCCText was able to be evaluated by using test items namely Field
Conceptual Change Inventory (FCCI) as understanding (U), misconceptions (M), no understanding (NU), partial understanding (PU) and no code (UC) the neutral object conceptions for re-conceptualizing the concepts to be more scientific conceptions (or conceptual change process as given by Table I and better prepare in exploring the next learning activities.

TABLE I. FREQUENCY AND PROPORTION OF STUDENTS' RESPONSES FOR TEST ITEMS.

\begin{tabular}{|c|c|c|c|c|c|}
\hline \multirow{3}{*}{ Category } & \multicolumn{3}{|c|}{ Neutral object conceptions } & \multirow{2}{*}{$\begin{array}{c}\text { \% Conceptual } \\
\text { Change }\end{array}$} \\
\cline { 2 - 5 } & \multicolumn{2}{|c|}{$\begin{array}{c}\text { Phase I of } \\
\text { VMMSCCText }\end{array}$} & \multicolumn{2}{c|}{$\begin{array}{c}\text { Phase IV of } \\
\text { VMMSCText }\end{array}$} & \\
\cline { 2 - 5 } & $f$ & $\%$ & $F$ & 90.91 & +90.73 \\
\hline U & 4 & 0.18 & 20 & 9.09 & -72.73 \\
\hline M & 18 & 81.82 & 2 & 0 & -9.09 \\
\hline NU & 2 & 9.09 & 0 & 0 & 0 \\
\hline PU & 0 & 0 & 0 & 0 & 0 \\
\hline UC & 0 & 0 & 0 & & \\
\hline
\end{tabular}

The data shows that the students' understanding increase (positive "+" sign) from phase I of VMMSCCText to phase II of VMMSCCText. It means that the VMMSCCText could effectively increase the learning process on neutral object conceptions and the same time the model could reconceptualize the students' conceptions. This is supported by research conducted by [20], the VMMSCCText can improve learning progression and CCText supported virtual simulation very effectively to remediate misconceptions [8].

\section{CONCLUSION}

Established on the analysis data, it can be concluded that the development of VMMSCCText on the neutral object through ADDIE developing model (Analyzing, Design, Development, Implementation, and Evaluation) was able to effectively increase the pre-service elementary school teachers understanding on the neutral object.

\section{REFERENCES}

[1] Beerenwinkel, A, Fostering Conceptual Change in Chemistry Classes Using Expository Texts. Unpublished Ph.D. Thesis, Bergischen Universität, Wuppertal, (2006).

[2] Chi, M. H., \& Roscoe, R. D., Reconsidering Conceptual Change: Issues in Theory and Practice. In M. Limon, \& L. Mason (Ed.), The Processes and Challenges of Conceptual Change. (pp. 3-27). Dordrecht: Kluwer Academic Publisher, (2002)

[3] Clement, J., Using Bridging Analogies and Anchoring Intuitions to Deal with Students' Preconceptions in Physics. Journal of Research in Science Teaching, 30 (10), 1241-1257, (1993)

[4] Tippett, C. D., Refutation Text in Science Education: A Review of Two Decades of Research. International Journal of Science and Mathematics Education, 8, 951-970, (2010)

[5] Akgün, A., The Relation between Science Student Teachers' Misconceptions about Solution, Dissolution, Diffusion and Their Attitudes toward Science with Their Achievement. Education and Science, 34 (154), 26-36. (2009)

[6] Şahin, Ç., İpek, H., \& Çepni, S., Computer Supported Conceptual Change Text: Fluid Pressure. Procedia Social and Behavioral Sciences, 2, 922-927, (2010) 
[7] Cepni S, Tas E, Kose S., The effects of computer-assisted materials on students' cognitive levels, misconceptions and attitudes towards science. Comp Educ 2006;46:192-205, (2006)

[8] Samsudin, Suhandi, Rusdiana, Kaniawati and Coştu, Investigating the effectiveness of an active learning based-interactive conceptual instruction (ALBICI) on electric field concept. Asia-Pacific Forum on Science Learning and Teaching, Volume 17, Issue 1, Article 1 (Jun. 2016)

[9] Sinclair Kesley J, Renshaw CE \& Taylor HA., Improving computerassisted instruction in teaching higher order skills. Comp Educ 2004;42:169-180, (2004)

[10] Roth, K. J., Conceptual Change Learning and Students' Processing of Science Text. Annual Meeting of the American Education Research Association. Chicago, (1985)

[11] Chambers, S. K., \& Andre, T., Gender, Prior Knowledge, Interest, and Experience in Electricity and Conceptual Change Text Manipulations in Learning about Direct Current. Journal of Research in Science Teaching, 34 (2), 107-123, (1997)

[12] She H, Lee CQ., SCCR Digital learning system for scientific conceptual(a change and scientific reasoning. Comp Educ 2008;51:724742, (2008)

[13] Akpinar \& Tan, Developing, Implementing, And Testing A Conceptual Change Text About Relativity. Western Anatolia Journal of Educational Sciences (WAJES), Dokuz Eylul University Institute, Izmir, Turkey ISSN 1308-8971, (2011)
[14] Aydin, Pre-service Science Teachers' Views on Conceptual Change Strategies and Practices Carried out. International Journal of Psychology and Educational Studies, 2015, 2 (2), 21-34, (2015)

[15] Durmuş, J., \& Bayraktar, S.., Effects of Conceptual Change Texts and Laboratory Experiments on Fourth Grade Students' Understanding of Matter and Change Concepts. Journal of Science Education and Technology, 19, 498-504, (2010)

[16] İpek, H., \& Çalık, M., Combining Different Conceptual Change Methods within Four-Step Constructivist Teaching Model: A Sample Teaching of Series and Parallel Circuits. International Journal of Environmental and Science Education, 3 (3), 143-153, (2008)

[17] Ozkan \& Selcuk, Effect of Technology Enhanced Conceptual Change Texts on Students' Understanding of Buoyant Force. Universal Journal of Educational Research 3(12): 981-988, 2015 http://www.hrpub.org . DOI: 10.13189/ujer.2015.031205, (2015)

[18] Hapkiewicz, A., Finding a List of Science Misconceptions. MSTA Newsletter, 38(Winterí92), pp.11-14, (1992)

[19] Hermita N., Suhandi A. \& Syaodih E., Identifikasi Miskonsepsi konsep listrik statis pada mahasiswa calon guru sekolah dasar. Prosiding Seminar Nasional Pendidikan Dasar UPI Bandung, (2016)

[20] Hermita N., Suhandi A., Syaodih E. \& Samsudin A., Profil Learning Progression Mahasiswa Calon Guru SD Terkait Konsep Benda Netral Setelah Aktivitas VMMSCCText. Jurnal Pedagogika dan Dinamika Pendidikan. Vol 7 no 2. (2017) 